\title{
Ideas of Happy Sports in Chinese P.E.
}

\author{
Xiaoyan REN \\ Henan Quality Polytechnic, Pingdingshan, Henan, China
}

\begin{abstract}
Happy sports is a kind of advanced teaching idea and teaching method that emerged in Chinese modern teaching field, and it has become an important means of the current physical education teaching. Happy sports teaching method can significantly improve the teaching quality. But there happy sports development is faced with plight. Through analyzing objectives and problems of happy sports, put forward long-term effective mechanisms of happy sports.
\end{abstract}

KEYWORD: Happy sports; Chinese P.E.; long-term mechanisms; Physical constitution

\section{INTRODUCTION}

With the development of education in China, in the field of the modern teaching, emerged a large number of advanced teaching ideas and teaching methods, and there is no exception in the sports teaching. Now teaching methods derived from happy P.E. have been an important means of the current physical education teaching[1]. Happy P.E. teaching methods can make more harmonious teaching atmosphere and interactions between teachers and students, thus the teaching quality was improved. And these methods can make students attend sports consciously, improve autonomy and initiative of participation, make students enjoy the pleasure of sports, so as to realize the all-round development of intelligence and physique. With the rapid development of education in our country and the reform of teaching system, happy P.E. is becoming more popular in current sports teaching, and gets improvement and innovation, and thus has become the mainstream of the current sports teaching mode. In order to further improve the level of sports teaching, however, should also further strengthen the study of happy P.E. teaching methods, so as to make happy P.E. be more perfect and mature in the application of modern physical education, and lay the solid foundation for our country's P.E. development.

\section{OBJECTIVES OF HAPPY SPORTS}

\subsection{Short-term goals}

The ministry of education, the state general administration of sports and the Central Communist Youth League in China point out in the decision of carrying out happy sports among hundreds of millions of national students: 'Up to standards, strive for excellent, strengthen body' should be the shortterm goals of implementing happy sports. The decision also brought forward a schedule that in 3 years, more than $85 \%$ of high schools were able to fully implement 'student physical health standard', and that make more than $85 \%$ of the students can do exercise an hour every day, and achieve the pass level in 'student physical health standard', and grasp at least two sports skills of daily exercises, and form good habits of physical training, to improve the levels of physical health.

\subsection{Long-term goals}

The long-term goals of happy sports should be determined to foster 'self-conscious healthy talents'. That is, the long-term goals are not only make hundreds of millions of students participate in sports and improve their physical health status, but to improve the students' life-long physical health level and the comprehensive quality of lifelong sports. And complete the strategy of happy sports as an important breakthrough of the all-round quality education, deepening the reform of quality education in our country, improving students' comprehensive quality level [2]. 
The specific objectives of 'self-conscious healthy talents' are: cultivating a lifelong interest in sport, the formation of lifelong sports consciousness, grasping the lifelong sports knowledge, improving the ability of lifelong sports, forming lifelong exercise habit, learning to self care, adhering to the lifelong sports and maintaining a healthy life.

\subsection{Strategic goals}

American experts that develop beneficial, energetic body entertainments are the need of contemporary society. British relevant believe that people should develop positive and happy attitudes to spend spare time. Japan and South Korea scholars emphasize culturing the abilities and attitudes of taking part in sports practice during lifetime. Throughout sports education ideas and goals in nations, it can be found that fully tapping the individual value, promoting the students' knowledge in physical and emotional aspects, cultivating the students' interest and active participation enthusiasm, establishing the idea of lifelong sports and serving the society, are their common characteristics. Therefore, 'happy sports among hundreds of millions of national students' should be a substantive strategic project that has long-term and integrative characteristics in time and space, and scientific and effective characteristics in theory and practice.

From the view of the sociology of students, families and society, we identify students as objects of strategic target. From the view of physical health education is 'social general consensus and identity', we take developing 'self-conscious healthy talents' as the breach of the implementation of strategic goals. Students have important positions and influences in families, so when they are cultivated to 'self-conscious healthy talents', they will influence families so as to the whole society[3]. Make the slogan 'health first' and 'Exercise one hour a day, work healthily for 50 years, and live a whole happy life.' be widely known and impressed, so as to promote the national physical health level in an allround way.

\section{THE PLIGHT OF THE HAPPY SPORTS DEVELOPMENT}

Happy sports development must accommodate the social practice and adapt to the development of the society. In order to better implement the happy sports among hundreds of millions of national students, we must do a good job of the school sports teaching to make students feel the fun of sports from the school sports teaching, form the habit of exercise consciously, and improve the physical education learning initiative. But at present in our national universities and colleges, there are some specific difficulties that are not appropriate to the happy sports plans, mainly manifested in the following respects.

\subsection{Exam-oriented education is still the biggest obstacle}

While advocating quality-oriented education has been for many years, the baton role of the college entrance examination is still very strong. In order to improve their reputation or influence, some schools still mainly concentrate on the pursuit of graduation rates. In many schools the attitudes toward P.E. tend to be 'talks major, does minor.' Even in some schools they try education instead of quality-oriented education, 'entrance first' instead of 'health first'. People's attitudes toward the school P.E. determine the school P.E. development. Schools and society all showed different degrees of neglect.

\subsection{Teacher resources need to be improved}

Sports teachers are the organizers and implementers school P.E. How to correctly handle the relationship between teaching and learning, give full play to teachers' leading role, and actively mobilize the students' dominant role, is the key to improve physical education teaching. Carrying on Happy P.E. puts forward higher request on the sports teachers. At present the full-time physical education teachers are far short of the requirements, especially in rural schools, almost no professional sports teachers. Even if equipped with part-time teachers, most of these teachers do not have received professional sports training. In some P.E. classes, teaching tasks will just be fulfilled that teachers lead students to run a little on the playground, or play a little on the playground, and without injury accident[4]. So, the current P.E. teacher resources can not meet the need of happy sports development. Because, only highly qualified physical education teachers mastering many skills while specializing in majors can help the students master the knowledge and method of scientific exercise, hold sports games for students, introducing high-level sports into campus, actively carry out competitive and mass sports activities, and active campus sports life according to the school actual situation.

\subsection{Consciousness of the students taking part in physical exercise is weak}

Physical exercise consciousness includes people's understanding of sports, attitude towards physical exercise and emotion, and adjustment of physical exercise behavior. Physical exercise consciousness is a conscious reflection on nature, characteristics, value of sports, as well as relationships between sports and people, and sports and other things. The 
strength of the consciousness of physical exercise plays promoting or impeditive impacts on physical exercise behavior. So developing good physical exercise consciousness is the important condition to promote physical exercise habit. The formation of the consciousness of physical exercise is not innate, yet it is gradually formed during the acquired family and school education, with the subtle influence of social environment, and by the practice of participating in sports activities.

\section{ESTABLISH LONG-TERM EFFECTIVE MECHANISM OF HAPPY SPORTS}

\subsection{The starting point of Happy sports should be cultivating the students' subjectivity}

Cultivate students' enthusiasm, consciousness and creativity of taking part in physical exercises. So that students can fully show individual character. So, happy sports are also the process of shaping students' subjective consciousness itself. And the formation of subjective consciousness enables the students to fully enjoy happiness and pleasure of sport. At the same time P.E. teachers will truly play dominant roles. Thus make the sports teaching and extracurricular activities in the process of the implementation full of humanity, and is permeated with freedom, harmony, love, equality, emotions and enchantment. In such comfortable environment, students are no longer depressed, strained and fearful. They can choose sport items according to their own interests, needs, special features and physical quality. And thus form the atmosphere of everyone involved and all rushing to good.

\subsection{Happy sports should pay attention to improve the interests of activities to arouse the students' sporting interests}

Enjoyment in Happy sports plays a 'locomotive' and the 'engine' role. Having fun and happy feeling are important reasons of taking part in physical exercises. So, happy sports focus on rich and colorful, interesting activities and organization forms. Activities such as sports dance, badminton, rubber band skipping, shuttlecock kicking, jumping lattice, etc. Organization forms such as group broadcast gymnastics, fun sports meet, class basketball match, happy-sports field, etc. In happy P.E. classes, in order to improve interests of the activity, the first thing of physical education teachers is to design interesting sports teaching method. Second, there are many different types of sport programs, so teachers should choose different sport items according to students' age, gender, health status and personality. At the same time pay attention to the categorization of different types of projects targeted, rationality of the content level, and strive to keep moderate difficulty and appropriate exercise intensity.

\subsection{Establish the integrative organization}

Longitudinal mechanism is to build a physical education integration leading group of school, family and community. The group members are mainly composed of school leaders, community leaders and parent representatives. It is responsible for researching and developing annual plans of the physical education integration, and organizing the implementation; and making regulations and system of the physical education integration, and makes its gradually standardized and institutionalized[5]. Transverse mechanism is to build a coordinating committee of school sports and community sports, school sports and family sports, family sports and community sports. Coordinating committee is directly led by the physical education integration leading group, and is responsible for by the physical education teachers and parents, community sports instructors. The committee members are P.E. teachers, community sports instructors and students' parent representatives. It is responsible for guiding schools, families and communities carrying out the elementary student's sports activities, sports learning counseling activities, holding sports exchanges, and coordinating sports material resources and sports human guiding resources, etc. the manage mode of physical education integration for school, family and community belongs to regional education socialization management mode. In theory, its organization, management and implementation can ensure benign operation of the physical education integration network.

\section{CONCLUSIONS}

In conclusion, the key to happiness sports is implementation. Establish the correct orientation of P.E., cultivate the students' subjectivity, improve the activity of interest, arouse the students' sporting interests, and establish the integrative organization. Only the majority of the students actively participates in sports, each one form the concept of lifelong sports and builds a strong physique. So as to realizes the purpose and task of happy sports.

\section{REFERENCES}

[1] Xiao Yang. College sports curriculum evaluation under the background of sunshine sports. China adult education, 2013(2):186-187

[2] Weijun $\mathrm{Wu}$. The study of the mechanism of sunshine sports in common colleges and universities. Journal of Hubei Radio \& Television University, 2010, 30(1):158-159 
[3] Fei Zhong. Investigations of normal university to carry out the the sunshine sports in East China. Sports, 2014, 94(7):54-55

[4] Jian Chen. Sunshine sports practice study. School party construction and ideological education, 2013(445):85-86
[5] Wenxin Xu. Long-term mechanism of happy sports in common universities. Scientific and technological information, 2010(36):27-29 